\title{
POLIMERIC MEMBRANES PREPARED WITH SURFACTANTS USED FOR ULTRAFILTRATION OF AQUEOUS SOLUTIONS OF FOOD DYE
}

\author{
GEORGE ALEXANDRU POPA ${ }^{\mathrm{a}}$, GHEORGHE NECHIFOR ${ }^{\mathrm{a},{ }^{,},}$ \\ DANIELA FLORENTINA ENACHE (POPA) ${ }^{a}$, \\ SZIDONIA-KATALIN TANCZOS ${ }^{b}$, ADRIAN CIOCANEA $^{c}$
}

\begin{abstract}
The experiments carried out in this paper tested the effectiveness of the polysulfone-dimethyldioctodecylammonium bromide (PSU-DMOA) and polysulfone-Tween 80 in dead-end facilities. The efficiency of these membranes has been proved by determining the permeate flow and the retention coefficient. Analyzing the experimental data, it was found that for the polysulfone-dimethyldioctodecylammonium bromide composite membrane the retention rate is higher than for the polysulfone-Tween 80 composite membrane, the $t$ values being obtained for the highest pressure used in the system.
\end{abstract}

Keywords: composite membranes, ultrafiltration, surfactants, food dye

\section{INTRODUCTION}

Polymeric membranes can be used in many simple and complex systems [1-3]. Obtaining membranes can be influenced by the addition of small amounts of surfactants $[4,5]$. The membrane process can be controlled by using surfactants $[6,7]$.

a University Politehnica of Bucharest, Department of Analytical Chemistry and Environmental Engineering, 1-3 Gh. Polizu Str.,011061, Bucharest, Romania

b Sapientia University, Liberty St., 500104, Miercurea Ciuc, Romania

c Politehnica University of Bucharest, Power Engineering Faculty-Hydraulics, Hydraulic Machinery and Environmental Engineering Department, 313 Splaiul Independentei, 060042, Bucharest, Romania

*Corresponding author: gheorghe.nechifor@upb.ro 
Surfactants are chemicals which, in solutions, concentrate on the surface and solubilize materials that have little affinity with each other [8]. Accumulating on the separation surfaces, the surfactants are able to alter strongly, even in very low concentrations, the superficial properties of the liquids in which they dissolve [9-11].

The composite polymeric membranes are currently one of the most viable solutions for increasing process membrane performance in terms of permeability as well as selectivity [12-15]. Currently, the improvement of the membrane techniques culminated in their transition to the industrial area of applicability $[16,17]$.

This paper presents the experimental results obtained from the use of polysulfone-dimethyldioctodecylammonium bromide (PMU-DMOA) and polysulfone-Tween 80 composite.

\section{RESULTS AND DISCUSSION}

Experiments were carried out to test the effectiveness of polysulfonedimethyldioctodecylammonium bromide (PMU-DMOA) and polysulfone-Tween 80 membranes. The efficiency of these membranes has been proved by the calculation of permeate flow and retention coefficient [18-22].

The results obtained for the polysulfone-dimethyldioctodecyl ammonium bromide (PMU-DMOA) membranes:

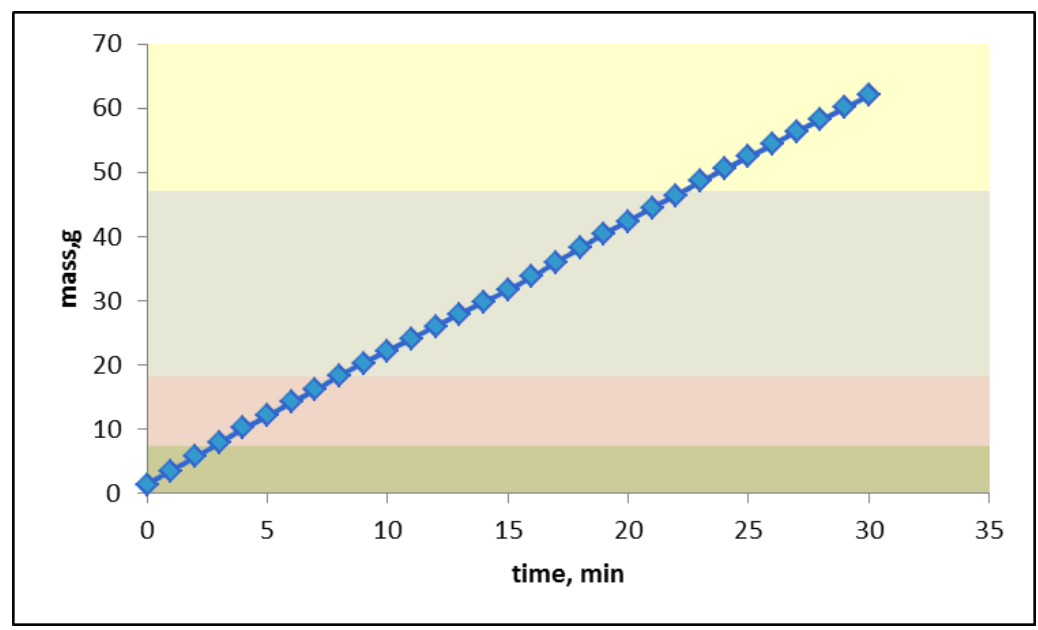

Figure 1. Time variation of the permeate mass at $0.1 \mathrm{MPa}$ pressure for polysulfone - dimethyldioctodecylammonium bromide 


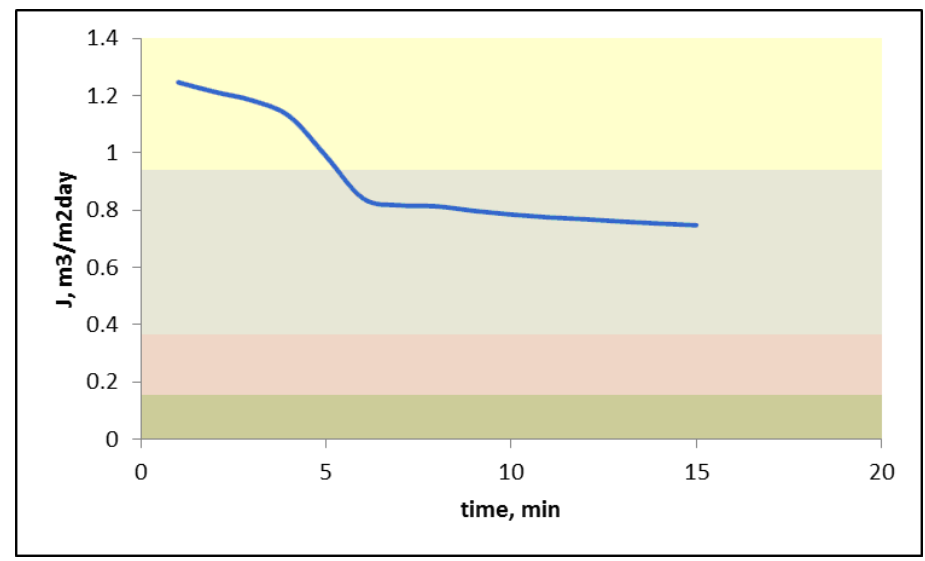

Figure 2. Flow variation at $0.1 \mathrm{MPa}$ for polysulfone dimethyldioctodecylammonium bromide

Working conditions: Initial solution: $\mathrm{C}_{18} \mathrm{H}_{13} \mathrm{NO}_{5 / 8 / 11} \mathrm{~S}_{1 / 2 / 3} \mathrm{Na}_{1 / 2 / 3}, 10 \%$ (equivalent to $100 \mathrm{~g} / \mathrm{m}^{3}$ ) - E104; Process duration: 30 minutes; Spectrophotometric measurements at the wavelength of $575 \mathrm{~nm}$; Initial temperature: $21,1^{\circ} \mathrm{C}$; Final temperature: $23,8^{\circ} \mathrm{C}$; Pressure: $0.1 \mathrm{MPa}$; Operation of the installation: dead-end.

Compared to classical polysulfone membranes, the membrane incorporating surfactant has a better flow for the same operating pressure, ranging from 0,7471 to $1,2463 \mathrm{~m}^{3} / \mathrm{m}^{2}$ day.

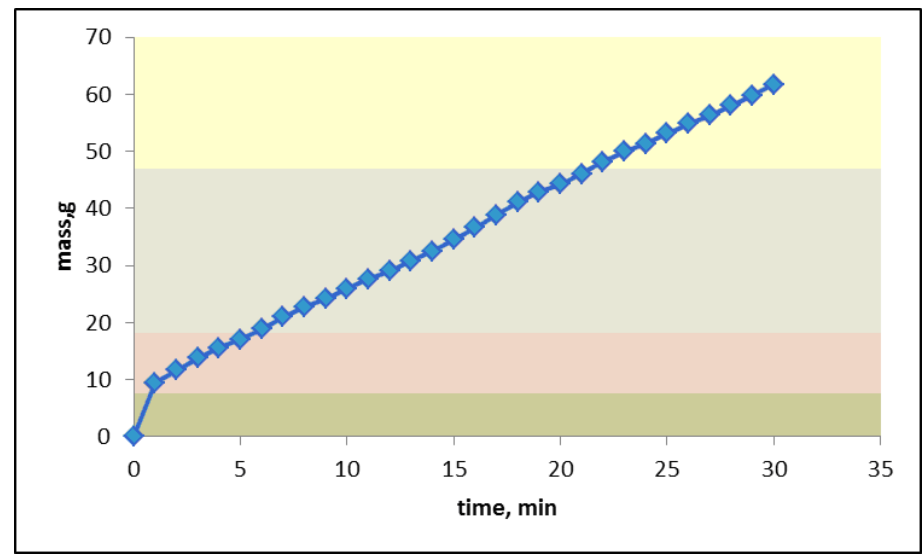

Figure 3. Time variation of the permeate mass at $0.2 \mathrm{MPa}$ pressure for polysulfone -dimethyldioctodecylammonium bromide 


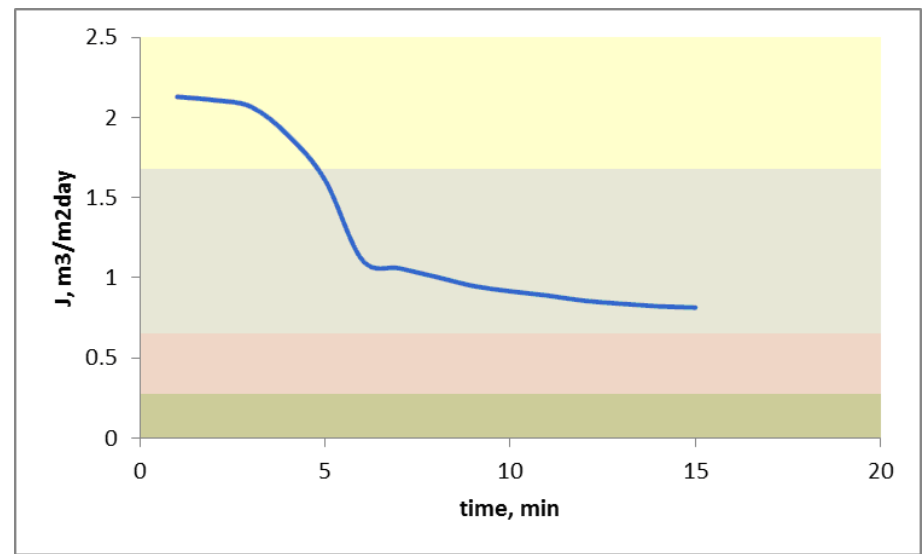

Figure 4. Flow variation at $0.2 \mathrm{MPa}$ for polysulfone dimethyldioctodecylammonium bromide

Working conditions: Initial solution: $\mathrm{C}_{18} \mathrm{H}_{13} \mathrm{NO}_{5 / 8 / 11} \mathrm{~S}_{1 / 2 / 3} \mathrm{Na}_{1 / 2 / 3}, 10 \%$ (equivalent to $100 \mathrm{~g} / \mathrm{m}^{3}$ ) - E104; Process duration: 30 minutes; Spectrophotometric measurements at the wavelength of $575 \mathrm{~nm}$; Initial temperature: $21,3^{\circ} \mathrm{C}$; Final temperature: $23,1^{\circ} \mathrm{C}$; Pressure: $0.2 \mathrm{MPa}$; Operation of the installation: deadend.

For the same solution analyzed, at a pressure of $0.2 \mathrm{MPa}$, the flow value ranged between 0,8145 and $2,129 \mathrm{~m}^{3} / \mathrm{m}^{2}$ day, considerably higher than those obtained under the same conditions at $0.1 \mathrm{MPa}$.

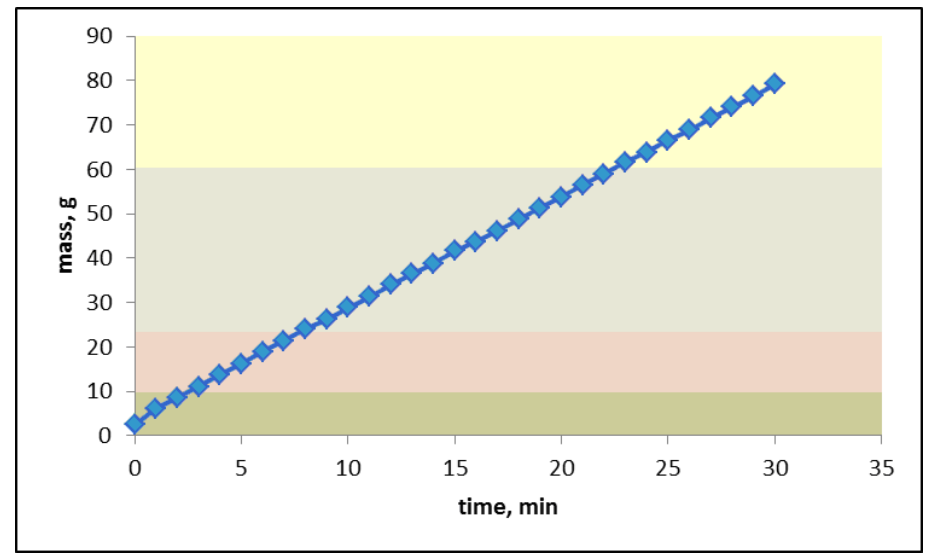

Figure 5. Time variation of the permeate mass at $0.3 \mathrm{MPa}$ pressure for polysulfone - dimethyldioctodecylammonium bromide 


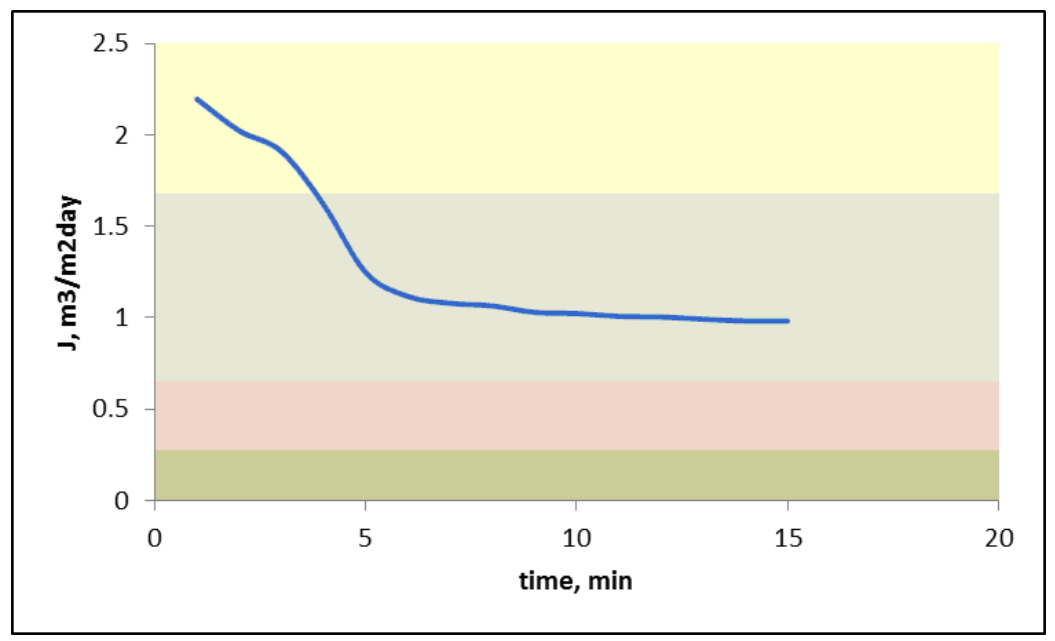

Figure 6. Flow variation at $0.3 \mathrm{MPa}$ for polysulfone dimethyldioctodecylammonium bromide

Working conditions: Initial solution: $\mathrm{C}_{18} \mathrm{H}_{13} \mathrm{NO}_{5 / 8 / 11} \mathrm{~S}_{1 / 2 / 3} \mathrm{Na}_{1 / 2 / 3}, 10 \%$ (equivalent to $100 \mathrm{~g} / \mathrm{m}^{3}$ ) - E104; Process duration: 30 minutes; Spectrophotometric measurements at the wavelength of $575 \mathrm{~nm}$; Initial temperature: $20,2^{\circ} \mathrm{C}$; Final temperature: $24,5^{\circ} \mathrm{C}$; Pressure: $0.3 \mathrm{MPa}$; Operation of the installation: deadend;

The flow value ranges from 0,9818 to $2,1577 \mathrm{~m}^{3} / \mathrm{m}^{2}$ day, also maintaining a downward trend. The flow values for the highest pressure are also high. It can be seen that the polysulfone-dimethyldioctodecyl ammonium bromide composite membrane presents a better flux compared to the polysulfone membrane and polysulfone-polyaniline membrane.

Also, the degree of retention for this type of membrane was higher, given that the presence of the surfactant in the membrane structure caused the formation of micelles and the retention of a considerable amount of dye. The retention determined for the composite polysulfone-dimethyldiocto decylammonium bromide membrane is shown graphically below.

The retention coefficient for solution containing dye E 104 ranged from 34,3 to $43,8 \%$ for composite membranes made of polysulfonedimethyldioctodecylammonium bromide using dead-end filtration. To determine the retention coefficient, we measured the concentration of permeate and retentate solutions using spectrophotometric measurements of absorbance at the wavelength of $575 \mathrm{~nm}$. 
G. A. POPA, GH. NECHIFOR, D. F. ENACHE (POPA), SZ.-K. TANCZOS, A CIOCANEA

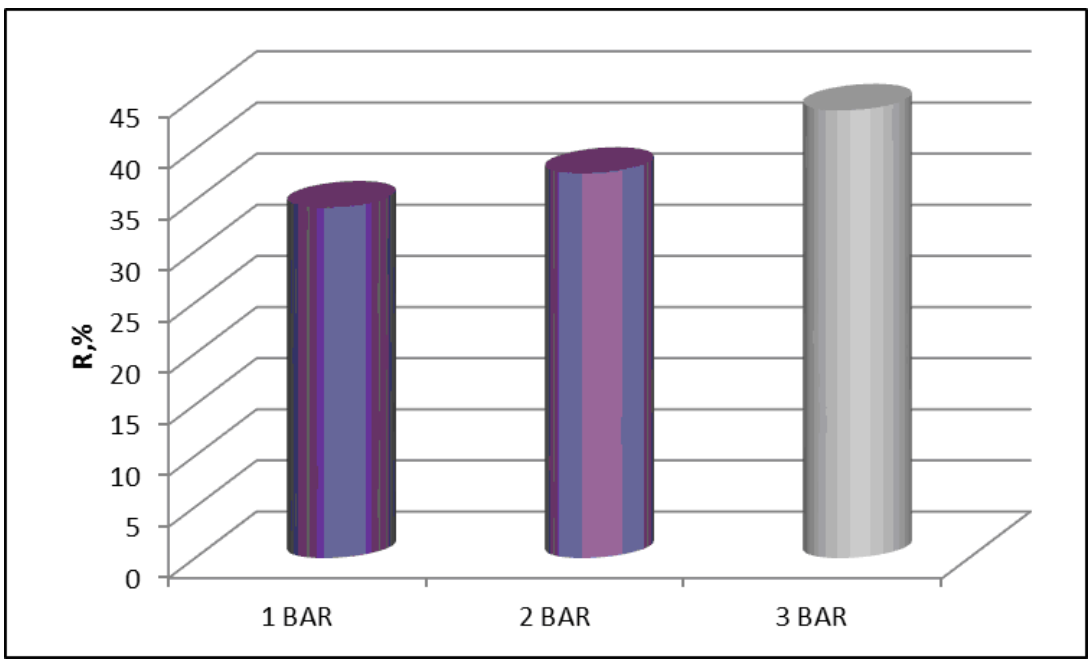

Figure 7. The retention ratio of the dye $(R)$ for the polysulfonedimethyldioctodecylammonium bromide

The results obtained for polysulfone - Tween 80 composite membrane:

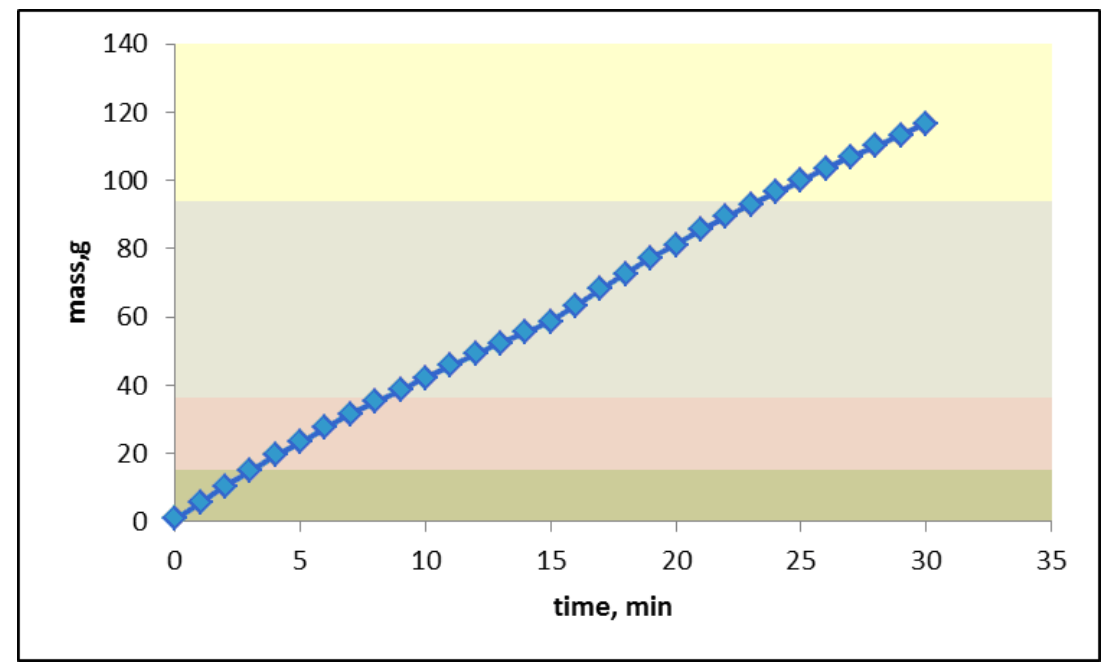

Figure 8. Time variation of the permeate mass at $0.1 \mathrm{MPa}$ pressure for polysulfone - Tween 80 


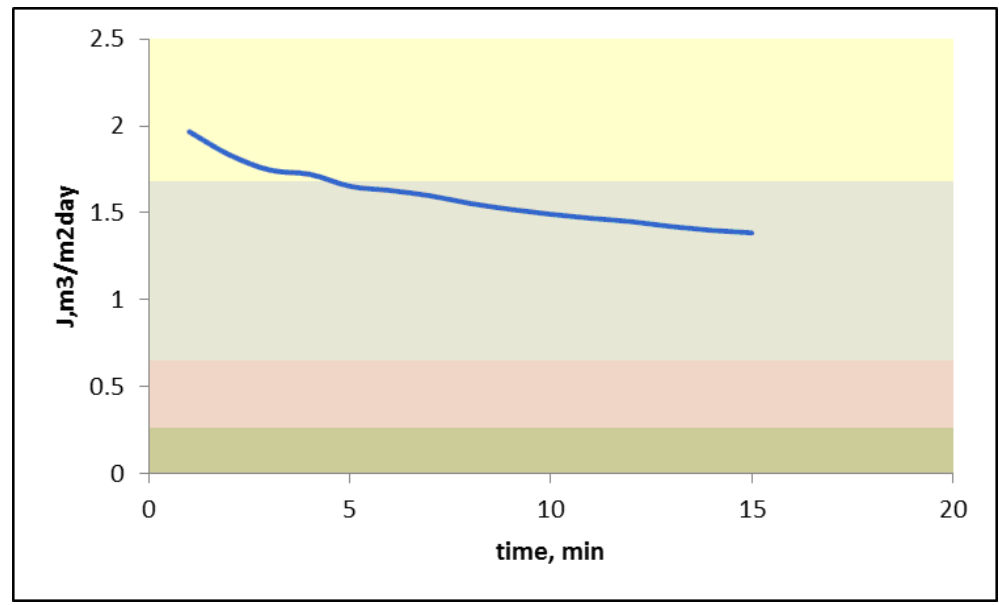

Figure 9. Flow variation at $0.1 \mathrm{MPa}$ for polysulfone - Tween 80

Working conditions: Initial solution: $\mathrm{C}_{18} \mathrm{H}_{13} \mathrm{NO}_{5 / 8 / 11} \mathrm{~S}_{1 / 2 / 3} \mathrm{Na}_{1 / 2 / 3}, 10 \%$ (equivalent to $100 \mathrm{~g} / \mathrm{m}^{3}$ ) - E104; Process duration: 30 minutes; Spectrophotometric measurements at the wavelength of $575 \mathrm{~nm}$; Initial temperature: $19,8^{\circ} \mathrm{C}$; Final temperature: $21,4^{\circ} \mathrm{C}$; Pressure: $0.1 \mathrm{MPa}$; Operation of the installation: dead-end.

For this membrane, flows were obtained which varied at an operating pressure of $0.1 \mathrm{MPa}$, from 1,3862 to $1,9671 \mathrm{~m}^{3} / \mathrm{m}^{2}$ day.

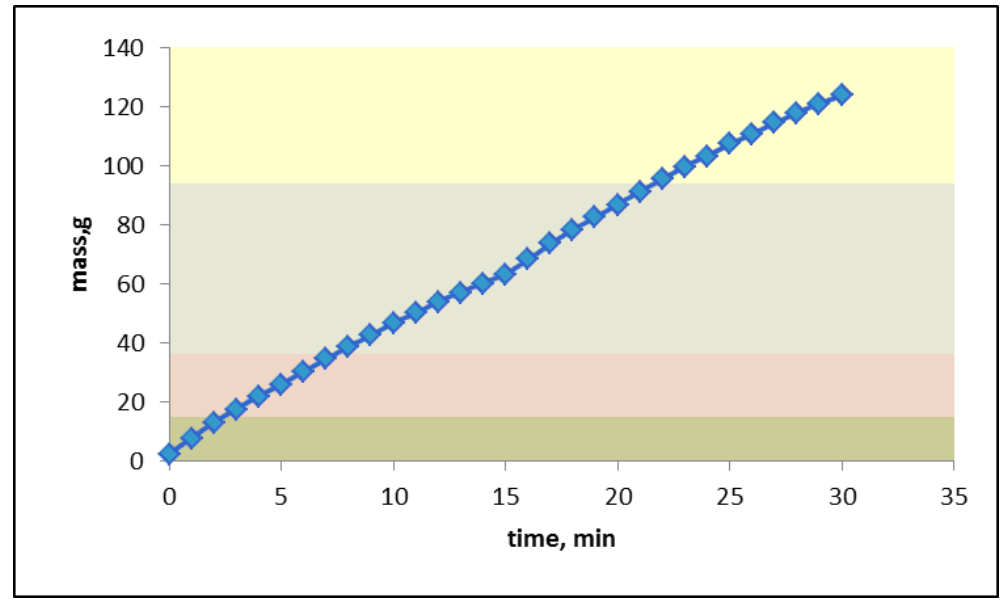

Figure 10. Time variation of the permeate mass at $0.2 \mathrm{MPa}$ pressure for polysulfone - Tween 80 


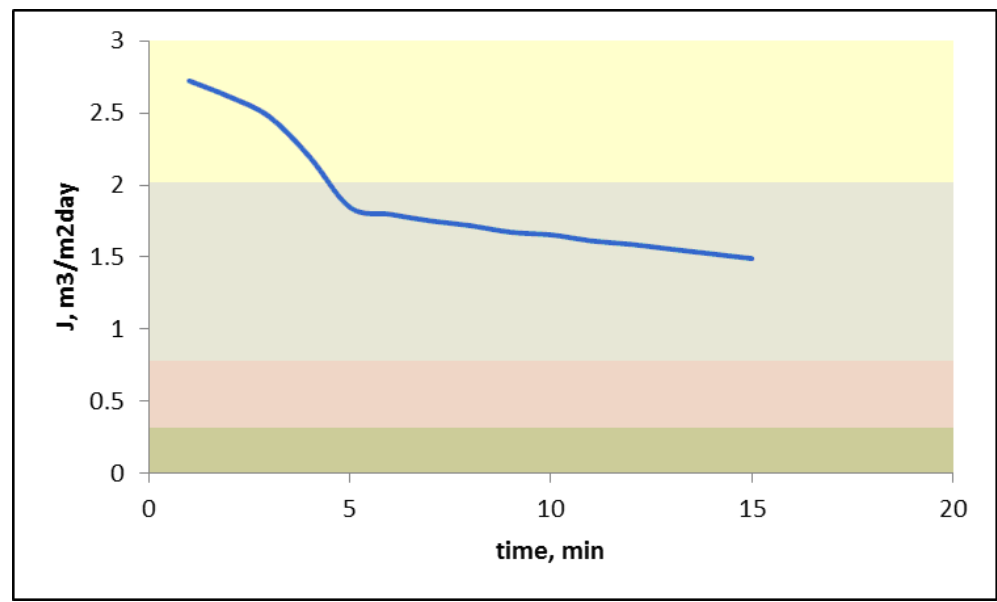

Figure 11. Flow variation at $0.2 \mathrm{MPa}$ for polysulfone - Tween 80

Working conditions: Initial solution: $\mathrm{C}_{18} \mathrm{H}_{13} \mathrm{NO}_{5 / 8 / 11} \mathrm{~S}_{1 / 2 / 3} \mathrm{Na}_{1 / 2 / 3}, 10 \%$ (equivalent to $100 \mathrm{~g} / \mathrm{m}^{3}$ ) - E104; Process duration: 30 minutes; Spectrophotometric measurements at the wavelength of $575 \mathrm{~nm}$; Initial temperature: $20^{\circ} \mathrm{C}$; Final temperature: $22,2^{\circ} \mathrm{C}$; Pressure: $0.2 \mathrm{MPa}$; Operation of the installation: deadend.

For the $0.2 \mathrm{MPa}$, the flow value is between 1,491 and $2,7226 \mathrm{~m}^{3} / \mathrm{m}^{2}$ day, considerably higher than those obtained under the same conditions at $0.1 \mathrm{MPa}$.

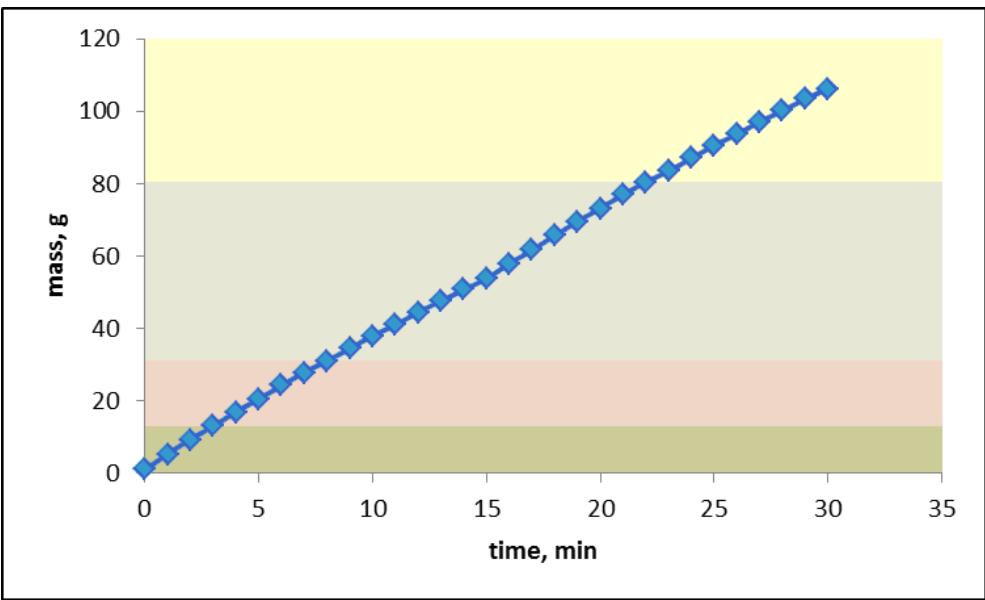

Figure 12. Time variation of the permeate mass at $0.3 \mathrm{MPa}$ pressure for polysulfone - Tween 80 


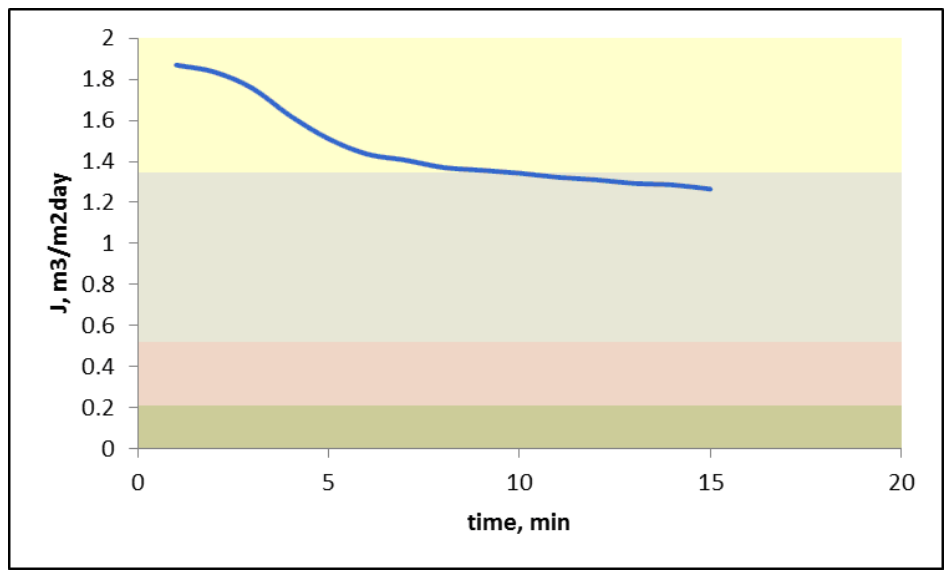

Figure 14. Flow variation at $0.3 \mathrm{MPa}$ for polysulfone - Tween 80

Working conditions: Initial solution: $\mathrm{C}_{18} \mathrm{H}_{13} \mathrm{NO}_{5 / 8 / 11} \mathrm{~S}_{1 / 2 / 3} \mathrm{Na}_{1 / 2 / 3}, 10 \%$ (equivalent to $100 \mathrm{~g} / \mathrm{m}^{3}$ ) - E104; Process duration: 30 minutes; Spectrophotometric measurements at the wavelength of $575 \mathrm{~nm}$; Initial temperature: $20,3^{\circ} \mathrm{C}$; Final temperature: $24,2^{\circ} \mathrm{C}$; Pressure: $0.3 \mathrm{MPa}$; Operation of the installation: deadend;

The flow rate at $0.3 \mathrm{MPa}$ is between 1,2657 and $1,8695 \mathrm{~m}^{3} / \mathrm{m}^{2}$ day. For this type of membrane, the best fluxes were obtained for the pressure of $0.2 \mathrm{MPa}$, and for the other pressure values the data obtained is similar. The retention degree for this type of membrane can be compared to that obtained for the other membrane types, the results being represented graphically.

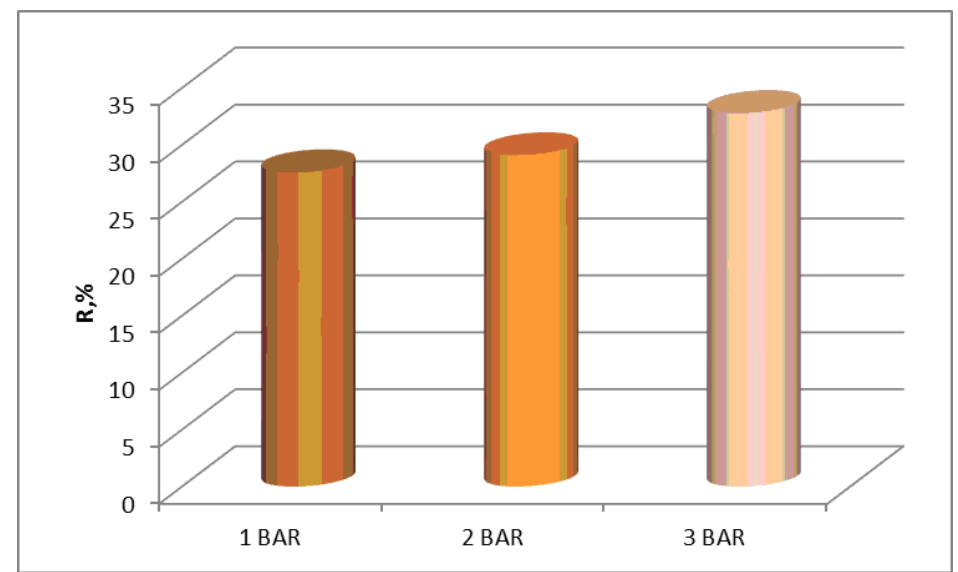

Figure 15. The retention ratio of the dye $(R)$ for the polysulfone - Tween 80 
The retention coefficient for solution containing dye $\mathrm{E} 104$ ranged from 27,6 to $32,8 \%$ for Tween 80 polysulfone - based composite membranes using dead - end filtration. The results are similar to those obtained for polysulfone polyaniline and polysulfone membranes.

To determine the retention coefficient, we measured the concentration of permeate and retentate solutions using spectrophotometric measurements of absorbance at the wavelength of $575 \mathrm{~nm}$.

\section{CONCLUSIONS}

Membranes undergoing this experimental study showed good mechanical and chemical resistance. Flows presented comparative values with literature data.

The best fluxes were obtained for the polysulfone - dimethyl dioctadecylammonium bromide membrane at $0.2 \mathrm{MPa}$ and at the highest pressure used in the instalation, $0.3 \mathrm{MPa}$ for the polysulfone - Tween 80 membrane.

Regarding the retention, it was observed that the best results were recorded for the dimethyldioctodecylammonium polysulfone - bromide membrane compared to the polysulfone - Tween 80 membrane.

\section{EXPERIMENTAL SECTION}

This study used non-commercial membranes [13-16]. The ultafiltration membranes developed were polysulfone-dimethyldioctodecylammonium bromide (PMU-DMOA) and polysulfone-Tween 80.

The properties of the ultrafiltration membranes regarding transport and separation were determined on solutions containing E104 quinoline yellow synthetic dye. The molecular formula of $E 104$ is: $\mathrm{C}_{18} \mathrm{H}_{13} \mathrm{NO}_{5 / 8 / 11} \mathrm{~S}_{1 / 2 / 3} \mathrm{Na}_{1 / 2 / 3}$ and the molecular weight amounts to $477.38 \mathrm{~g} / \mathrm{mol}$. It is used as a synthetic colouring agent in food and drink products, as well as in cosmetics.

The ultrafiltration process in the presence of surfactants was investigated in a pilot laboratory set - up [14]. The membrane being tested had a diameter of $36 \mathrm{~mm}$. The pressures used in the ultrafiltration process were 0.1 , 0.2 and $0.3 \mathrm{MPa}$. Permeate volume fluxes and retention coefficients were determined on steady flow conditions. Permeate volume flow was calculated as shown below: $J=\frac{V}{t \cdot A}\left(m^{3} / m^{2} d a y\right)$, where $\mathrm{V}$ is the permeate volume $\left(\mathrm{m}^{3}\right)$, $\mathrm{t}$ stands for the time (day), and A represents the effective membrane surface area $\left(\mathrm{m}^{2}\right)$. 
Dye retention coefficient $(\mathrm{R})$ was determined as: $R=\frac{C_{k}-C_{p}}{C_{k}} \cdot 100(\%)$ where $\mathrm{Ck}$ and $\mathrm{Cp}$ denote the dye concentration $\left(\mathrm{g} / \mathrm{m}^{3}\right)$ in retentate and permeate, respectively [16].

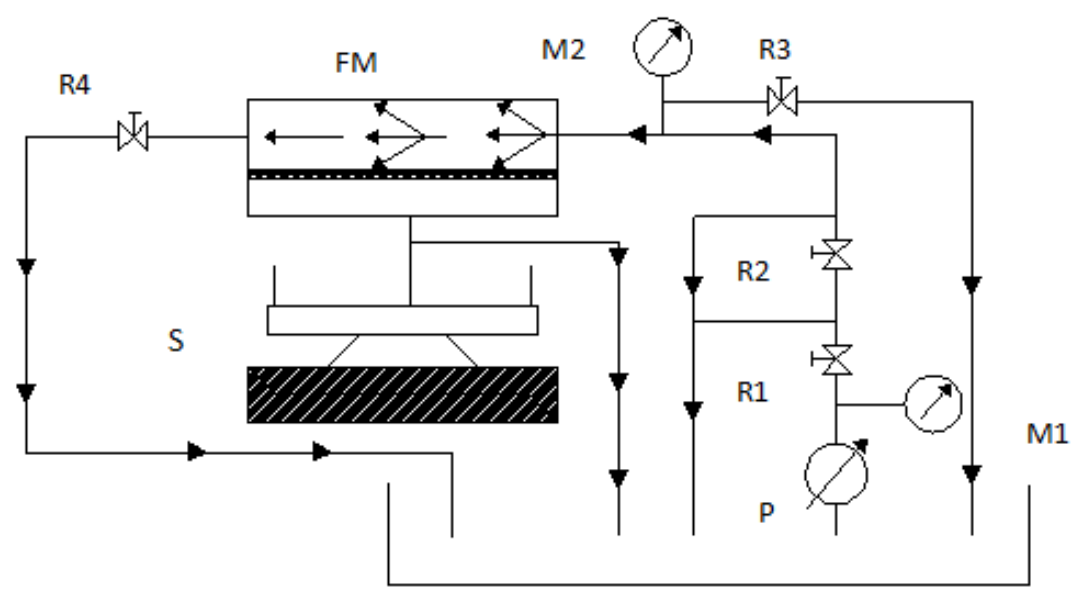

Scheme 1. Pilot set-up: $P$-centrifugal pump, $F M$ - filtration module, $S$-digital scale, $\mathrm{R}$ - valve, $\mathrm{M}$ - manometer

To obtain a wider range of flow a centrifugal pump was used $(Q=$ $40 \mathrm{l} / \mathrm{min}$ ), driven by a variable speed $(n=287 \mathrm{rpm})$. A digital laboratory balance, Mettler Toledo model, was used for weighing. The substrate surfaces used for the membranes will be molecular sieves, made of stainless steel. For this, AISI304MESH94 mesh sieve $110 \mu(0,11 \mathrm{~mm})$ mesh opening $150 \mu(0,15 \mathrm{~mm})$ was used. This is mainly used in the pharmaceutical industry. To track the flow parameters through the membrane, equipment has been developed to highlight these aspects.

\section{ACKNOWLEDGMENTS}

The work has been funded by UEFISCDI PN-II-PT-PCCA-2013-4-0742 Project for $\mathrm{PhD}$ students support and the Sectoral Operational Programme Human Resources Development 2007-2013 of the Ministry of European Funds through the Financial Agreement POSDRU/159/1.5/S/134398. 


\section{REFERENCES}

1. G. Nechifor, N. Luca, G. Popescu, M. Nechifor, Revue Roumaine de Chimie, 1989, 34, 2047.

2. G. Batrinescu, M.A. Constantin, A. Cuciureanu, G. Nechifor, Polymer Engineering and Science, 2014, 54, 1640.

3. K. Scott, „Handbook of industrial membranes”, First edition, Elsevier Science Publishers Ltd, 1995.

4. G., Nechifor, B. Albu, D. Rata, G. Popescu, Revista de Chimie, 1996, 47, 260.

5. K. Lintner, S. Bragulla, Internationale Zeitschrift fur Lebensmittel, 1987, 38, 120.

6. K. Majewska-Nowak, Environment Protection Engineering, 2009, 4, 111.

7. G. Nechifor, S.I. Voicu, A.C. Nechifor, S. Garea, Desalination, 2009, 241, 342.

8. E. Chifu, "Chimie coloidala" Editura Didactică şi Pedagogică, Bucuresti, 1969.

9. N. Rubingh, P. M. Holland (ed.), "Cationic Surfactants - Physical Chemistry", Marcel Dekker, New York, 1991.

10. M.J. Schick (ed.), "Nonionic Surfactants", Marcel Dekker, New York, 1966.

11. K.L. Mittal, D.O. Shoh, "Surfactants in solution", Vol. 11, Springer Science \& Business Media, New York, 1991.

12. B. Van der Bruggen, B. Daems, D. Wilms, C. Vandecasteele, Separation and Purification Technology, 2001, 22-23, 519.

13. Ştefan loan Voicu, Florin Aldea, Marin Răduţ, Gheorghe Nechifor, Nanostructured polysulfone composite membranes, U.P.B. Sci. Bull., Series B, 2008, 70, 3.

14. G.A. Popa, D.F. Popa (Enache), D.D. Slave (Clej), I.S. Din, C.M. Mirea, A., Ciocanea, Revista de Chimie, 2017, 68, 6.

15. A. Cuciureanu, G. Batrinescu, N.N. Badea, D.A. Radu, G. Nechifor, Materiale Plastice, 2010, 47, 416.

16. A.A.K.K. Rikabi, A. Cuciureanu, M. Chelu, A.R. Miron, C. Orbeci, A.G. Popa, M.E. Craciun, Revista de Chimie, 2015, 66,1093.

17. C.K. Kima, S.S. Kimb, J.C. Limc, J.J. Kimd, Journal of Membrane Science, 1998, 147, 13.

18. K. Majewska-Nowak, I. Kowalska, M. Kabsch-Korbutowicz, Desalination, 2006, 198, 157.

19. K. Majewska-Nowak, I. Kowalska, M. Kabsch-Korbutowicz, Desalination, 2006, 200, 283.

20. C.K. Kima, S.S. Kimb, J.C. Limc, J.J. Kimd, Journal of Membrane Science, 1998, 147,13.

21. A.C. Archer, A.M. Mendes, R.A.R. Boaventura, Environmental Science and Technology, 1999, 33, 2758.

22. K. Majewska-Nowak, Environment Protection Engineering, 2005, 31, 229.

23. J. Huang, L. Peng, G. Zeng, X. Li, Y. Zhao, L. Liu, F. Li, Q. Chai, Separation and Purification Technology, 2014, 125, 83. 